\title{
Early detection of septic arthritis caused by Streptococcus dysgalactiae subspecies equisimilis in a dog - a case report
}

\author{
Banu Dokuzeylül1, Kemal Metiner², Beren Başaran Kahraman², Abdullah Kayar ${ }^{1}$, \\ N. Yakut Özgür ${ }^{2}$
}

\begin{abstract}
Istanbul University, Faculty of Veterinary Medicine, ${ }^{1}$ Department of Internal Medicine, ${ }^{2}$ Department of Microbiology, Istanbul, Turkey
\end{abstract}

Received March 18, 2013

Accepted April 24, 2014

\begin{abstract}
In this report, a seven-year-old English Pointer male with Streptococcus dysgalactiae subsp. equisimilis arthritis joint infection is presented. The dog was referred to the Internal Medicine Department Policlinics with the symptoms of anorexia, weakness, swollen joints and ulcerative wounds on testes. On physical examination, the dog was depressed and manifesting discomfort during manipulation of the fore and hind legs' joints. There were palpable effusions of the right carpal, elbow, and tibiotarsal joints. Haematological and serum biochemical analyses showed mild anaemia, moderate thrombocytopaenia, and elevated alanine aminotransferase. As soon as the synovial fluid aspirates were obtained aseptically from the right elbow, radiocarpal, and tibiotarsal joints, they were sent to bacteriological examination. Symptomatic and supportive treatment was initiated immediately. Empirical enrofloxacin therapy was initially started. Bacteria which were cultivated from the synovial fluid aspirates specimen were identified as S. equisimilis. The isolate was found to be resistant to enrofloxacin and susceptible to amoxycillin/ clavulanic acid. According to the results of the antimicrobial susceptibility tests, enrofloxacin therapy was terminated and amoxycillin/clavulanic acid therapy was immediately started lasting for four weeks. The dog was treated successfully. To our knowledge, Streptococcus dysgalactiae subsp. equisimilis was isolated from the synovial fluid from a dog for the first time in Turkey, as it is rarely seen in dogs.
\end{abstract}

Streptococcus spp., arthritis, swollen joint, antimicrobial susceptibility

Infectious arthritis is a common problem usually caused by bacterial agents that affect various species including humans, horses, and dogs. Septic arthritis which may cause pain, swelling, and lameness, is usually a monoarthropathy in dogs. Several different bacteria species, especially Staphylococcus intermedius, $S$. aureus and $\beta$-haemolytic streptococci have been isolated from septic arthritis in dogs (Bennett and Taylor 1988; Clements et al. 2005). Lancefield group-C streptococci are a common cause of infection in animals but rarely detected in humans (Bradley et al. 1991). Streptococcus dysgalactiae subsp. equisimilis (S. equisimilis) is a large-colony type $(>0.5 \mathrm{~mm})$ Lancefield group C-haemolytic streptococcus that can rarely cause septic arthritis (Ike 1990). Septic arthritis may be suspected on the basis of clinical presentation: typically severe lameness and thickened painful joint(s) with or without concurrent systemic signs such as pyrexia, anorexia, and depression (Fearnside and Preston 2002).

\section{Clinical findings and medical treatment}

A seven-year-old English Pointer male, weighing $15 \mathrm{~kg}$, was referred to the Internal Medicine Department Clinics with anorexia, weakness, swollen joints (Plate VIII, Fig. 1) and ulcerative wounds on testes. The anamnesis included that the patient's owner had left the dog with his friend for 15 days. The dog's symptoms started to appear after that time and the dog's food intake started to decrease day by day.

Address for correspondence:

Banu Dokuzeylül, DVM, PhD

Istanbul University, Faculty of Veterinary Medicine

Department of Internal Medicine

Phone: +90212 4737070 (17131)

Avc1lar Campus, 34320, Avc1lar, Istanbul, Turkey 
On physical examination, the dog was depressed and exhibiting discomfort during manipulation of the fore and hind leg joints. The dog's rectal temperature was $39.6^{\circ} \mathrm{C}$ and the respiration rate was $23 / \mathrm{min}$. By palpation there were effusions of the right carpal, elbow, and tibiotarsal joints. No abnormality was detected on orthopaedic examination. It was checked with radiography and hand examination. The dog showed no abnormality during walking.

Haematological and serum biochemical analyses revealed mild anaemia (Haematocrit (HCT): $29 \%$ ), moderate thrombocytopaenia (Platelets (PLT): $150 \times 10^{3} \mu \mathrm{l}$ ) and elevated alanine aminotransferase (ALT): $275 \mathrm{IU} / 1$. Because it was a hunting dog, rapid tests for ehrlichiosis, anaplasmosis, dirofilariasis, Lyme disease $\left(\operatorname{Snap}^{\circledR}, 4 \mathrm{Dx}^{\mathbb{R}}\right.$, Idexx Laboratories, USA), and leishmaniasis (Snap ${ }^{\circledR}$ Leishmania, Idexx Laboratories, USA) were performed with a negative result.

Synovial fluid aspirates were obtained aseptically from the right elbow, radiocarpal, and tibiotarsal joints. The samples were sent to the Department of Microbiology laboratory for bacteriological examination, and inoculated onto Nutrient agar supplemented with 7\% sheep blood, MacConkey agar plates and into Nutrient broths. While MacConkey agar plates were incubated only aerobically, other plates were incubated aerobically, anaerobically, and microaerobically at $37^{\circ} \mathrm{C}$ for 24 to $48 \mathrm{~h}$. The colonies were observed macroscopically, and then microscopic observation of a gram stain was done. Further identification was performed by conventional biochemical activity tests and Lancefield serogrouping (Quinn et al. 1999). The antibiotic susceptibility test according to Kirby-Bauer method recommended by the CLSI was performed to select the convenient antimicrobial agent for treatment (CLSI document M100-S18 2008).

As soon as the samples for bacteriological examination were taken, symptomatic and supportive therapy was immediately started. The dog was an ambulatory patient. Serum transfusion therapy (5\% dextrose solution, $400 \mathrm{ml}$, IV), phenoxy methyl propionic acid (Hepagen, Vetaş, Turkey) at the dose of $1.5 \mathrm{ml} / \mathrm{dog} /$ day i.m., enrofloxacin (Baytril, Bayer, Turkey) at the dose of $1.5 \mathrm{ml} / \mathrm{dog}$ /day i.m., B complex vitamins (Berovit, Ceva, Turkey) 2 $\mathrm{ml} / \mathrm{dog} /$ day i.m., ranitidine (Ulcuran, Abfar, Turkey) at the dose of $1.2 \mathrm{ml} / \mathrm{dog}$, i.m. BID, vitamin E (Evicap, Koçak Farma, Turkey) at the dose of 200 IU/dog/day p.o., were applied for a week. Topical iodine therapy was applied to ulcerative wounds. Low protein diet was also advised to the dog's owner.

After one week from this therapy, haematological and serum biochemical analyses were made again at the Faculty's laboratory. Complete blood count indicators, HCT and PLT, were determined as $38 \%$ and $300 \times 10^{3} \mu 1$, respectively. Elevated ALT (275 IU/l) was decreased to $175 \mathrm{IU} / \mathrm{l}$. Fore and hind leg joints were again checked with radiography. No abnormalities were detected at the area of joints (Plate IX, Fig. 2).

Beta-haemolytic, 1-2 mm diameter, translucent colonies were observed as pure cultures on the blood agar plates. Characteristic Gram positive cocci in the chain formation were observed after Gram staining from broth culture. Streptococcus equisimilis was identified on the basis of bacteriological examination. The results of antimicrobial susceptibility testing indicated that the isolate was resistant to cloxacillin $(6 \mu \mathrm{g} / \mathrm{ml})$, enrofloxacin $(5 \mu \mathrm{g} / \mathrm{ml})$, erythromycin $(5 \mu \mathrm{g} / \mathrm{ml})$, gentamycin $(10 \mu \mathrm{g} / \mathrm{ml})$, lincomycin $(25 \mu \mathrm{g} / \mathrm{ml})$, rifampin $(25 \mu \mathrm{g} / \mathrm{ml})$, sulphamethoxazole/trimethoprim $(23.75 / 1.25 \mu \mathrm{g})$, and susceptible to ampicillin $(10 \mu \mathrm{g})$, amoxycillin/clavulanic acid $(20 / 10 \mu \mathrm{g})$, amoxycillin $(25 \mathrm{mg} / \mathrm{ml})$, ampicillin-sulbactam $(10 / 10 \mu \mathrm{g})$, ceftriaxone $(30 \mu \mathrm{g})$, cefoperazone $(75 \mu \mathrm{g})$, oxytetracycline $(30 \mu \mathrm{g} / \mathrm{ml})$, penicillin $\mathrm{G}$ (10 units), tetracycline $(20 \mu \mathrm{g} / \mathrm{ml})$, cephazolin $(30 \mu \mathrm{g} / \mathrm{ml})$, vancomycine $(30 \mu \mathrm{g} / \mathrm{ml})$, cephalothin $(30 \mathrm{mg})$, cephoxitin $(30 \mu \mathrm{g} / \mathrm{ml})$.

According to the results of the antimicrobial susceptibility tests, enrofloxacin therapy (Baytril ${ }^{\circledR}, 1.5 \mathrm{ml}$, i.m., SID) was terminated and amoxycillin/clavulanic acid (Synulox, Pfizer, Turkey) at the dose of $12.5 \mathrm{mg} / \mathrm{kg}$ p.o. BID treatment was immediately started. The 
antibiotic therapy lasted for 4 weeks. At this time, liver supportive therapy was continued with phenoxy methyl propionic acid (Hepagen, Vetaş, Turkey) at the dose of $1.5 \mathrm{ml} / \mathrm{dog} /$ day i.m., B complex vitamins (Berovit, Ceva, Turkey) $2 \mathrm{ml} / \mathrm{dog}$ /day i.m, vitamin E (Evicap, Koçak Farma, Turkey) at the dose of 200 IU/dog/day p.o., vitamin $C$ (Estervit $C^{\circledR}$ tab., 1 tab., p.o., SID). The dog's nutrition continued with a low protein diet.

After one month of amoxycillin/clavulanic acid therapy, the dog was referred to the Internal Medicine Department Clinic for a check-up. Remarkable improvements were noticed in general health status and blood analyses. The dog was alert and responsive. No abnormal clinical findings were detected. The dog gained weight $(17.5 \mathrm{~kg})$. The joint areas seemed normal and had no pain during palpation. The wound on testes was healed. HCT value was increased from $38 \%$ to $50 \%$. Elevated ALT (175 IU/1) was decreased to the reference range value (54 IU/1). When all the therapies were finished, the symptoms of the dog disappeared and the dog turned into a healthy condition (Plate IX, Fig. 3).

\section{Discussion}

Bacterial contamination of the joints happens through direct penetration (surgical or traumatic), haematogenous spread into local or neighbouring tissues (Baranyiova et al. 2003). The joint penetration wound has a potential to cause permanent damage. Early and effective interventions in cases of septic arthritis are fairly simple but effective treatment is difficult. However, if an appropriate therapy is delayed, it can transform into septic arthritis (Soontornvipart et al. 2003). In this case, swollen joints of the dog were noticed early.

Streptococcus. equisimilis is now thought to cause a range of infections, from relatively mild to severe life-threatening invasive diseases, such as acute pharyngitis, pyoderma, wound infections, abscesses, septic arthritis, vertebral osteomyelitis, septicaemia, multiple organ failure, and streptococcal toxic shock syndrome (Yoshida et al. 2011). The authors reported several septic arthritis cases (Parola et al. 1998; Marchevsky and Read 1999; Sipahi et al. 2008; Takashi et al. 2011). Yoshida et al. (2011) reported that it is much harder to identify potential arthritis caused by $S$. equisimilis infection. There are few data about septic arthritis cases caused by this agent. Steinfeld et al. (1997) recently reported a case of $S$. equisimilis septic arthritis in a patient with AIDS. Parola et al. (1998) reported a case of septic arthritis of the left ankle due to $S$. equisimilis in a patient who had contact with a horse. In Turkey, a case of 71-year-old male patient with $S$. equisimilis arthritis/ prosthetic joint infection was presented (Sipahi et al. 2008). In this case, we identified $S$. equisimilis from the synovial fluid of the dog for the first time in Turkey.

Authors of one study pointed out that the most important cause of septic arthritis, acute and chronic postoperative (seen in the knee joint) were joint infections (Bennett and May 1995). Synovial fluid, joint capsule and periarticular prosthetics and blood culture were noted as important for diagnosis (Marchevsky and Read 1999). In some cases, the authors reported that bacterial growth was not detected; it may be due to an application of antibiotics prior to taking the sample (Quinn et al. 1999). Bennett and Taylor (1988) detected bacterial growth and septic arthritis in $81 \%$ from the joint fluid, and $100 \%$ from the joint capsule. Montgomery et al. (1989) pointed out that the results of the joint fluid cultures were more sensitive than those of the joint capsule. In this case, bacterial arthritis was detected from the synovial fluid; our findings are similar to the results of these authors.

Frontos o et al. (2008) reported that Streptococcus group C, a clear and marked resistance (i.e. only $4.5-8.4 \%$ of bacterial strains being inhibited) was observed in gentamicin and enrofloxacin and the highest susceptibility was observed in amoxicillin/clavulanic acid with $82.7 \%$ of the isolates being inhibited. In this case, as soon as taking the samples for bacteriological examination, enrofloxacin (Baytril ${ }^{\circledR}, 1.5 \mathrm{ml}$, i.m., SID) was applied for a week. The results of antimicrobial susceptibility testing indicated that the isolate 
was resistant to enrofloxacin $(5 \mu \mathrm{g} / \mathrm{ml})$ and susceptible to amoxycillin/clavulanic acid $(20 / 10 \mu \mathrm{g})$. Our results supported Frontoso's results. Finally, in this case bacterial arthritis was detected and Streptococcus dysgalactiae subsp. equisimilis was isolated from the synovial fluid of the dog which is the first case in Turkey.

\section{References}

Baranyiova E, Holub A, Martinikova M, Nečas A, Zatloukal J 2003: Epidemiology of intraspecies bite wounds in dogs in the Czech Republic. Acta Vet Brno 72: 55-62

Bennett D, Taylor DJ 1988: Bacterial infective arthritis in the dog. J Small Anim Pract 29: 207-230

Bennett D, May C 1995: Joint diseases of dogs and cats. In: Ettinger SJ, Feldman EC (Eds): Textbook of Veterinary Internal Medicine. $4^{\text {th }}$ ed. Saunders, Philadelphia, pp. 2032-2077

Bradley SF, Gordon JJ, Baumgartner DD, Marasco WA, Kauffman CA 1991: Group C streptococcal bacteraemia: Analysis of 88 cases. Rev Infect Dis 13: 270-280

Clements DN, Owen MR, Mosley JR, Carmichael S, Taylor DJ, Bennett D 2005: Retrospective study of bacterial infective arthritis in 31 dogs. JSAP 46: 171-176

Clinical and Laboratory Standards Institute (CLSI): Performance standards for antimicrobial susceptibility testing. $18^{\text {th }}$ Informational Supplement. Approved Standard MS100-S18, 2008: CLSI, Wayne, PA.

Fearnside SM, Preston CA 2002: Arthroscopic management of septic polyarthritis in a dog. Aust Vet J 80: 681-683

Frontoso RE, De Carlo MP, Pasolini K, Van der Meulen U, Pagnini G, Iovane L, De Martino 2008: Retrospective study of bacterial isolates and their antimicrobial susceptibilities in equine uteri during fertility problems. Res Vet Sci 84: 1-6

Ike RW 1990: Septic arthritis due to group C streptococcus: report and review of the literature. J Rheumatol 17: $1230-1236$

Marchevsky AM, Read RA 1999: Bacterial septic arthritis in 19 dogs. Aust Vet J 77: 233-237

Montgomery RD, Long IR Jr., Milton JL, DiPinto MN, Hunt J 1989: Comparison of aerobic culturette, synovial membrane biopsy and blood culture medium in detection of canine bacterial arthritis. Vet Surg 18: 300-303

Parola P, Brouqui P, Maurin M, Bourgeade A 1998: A new case of Streptococcus equisimilis septic arthritis. Clin Rheumatol 17: 71-72

Quinn PJ, Carter ME, Markey B, Carter GR 1999: The streptococci and related cocci. In Quinn PJ (Eds): Clinical Veterinary Microbiology. Mosby, Edinburgh, pp. 127-136

Sipahi OR, Özkören Çalik S, Pullukçu H, Işikgöz Taşbakan M, Arda B, Tünger A, Ulusoy S 2008: Streptococcus equisimilis associated septic arthritis/prosthetic joint infection. Mikrobiyol Bul 42: 515-518

Soontornvipart K, Kohout P, Proks P 2003: Septic arthritis in dogs: a retrospective study of 20 cases (2000-2002). Acta Vet Brno 72: 405-413

Steinfeld S, Galle C, Struelens M, De Gheldre Y, Farber CM, Appelboom TH, Van Vooren JP 1997: Pyogenic arthritis caused by Streptococcus equisimilis (group C streptococcus) in a patient with AIDS. Clin Rheumatol 16: $314-316$

Takashi T, Kimiko U, Haruo W 2011: Invasive infection caused by Streptococcus dysgalactiae subsp. equisimilis: characteristics of strains and clinical features. J Infect Chemother 17: 1-10

Yoshida H, Matsui H, Yamagata Murayama S, Takada Y, Matsuo K, Takahashi T, Nakamura M, Ubukata K, Takahashi T 2011: A CD46 transgenic mouse model for studying the histopathology of arthritis caused by subcutaneous infection with Streptococcus dysgalactiae subspecies equisimilis. J Med Microbiol 60: $1860-1868$ 
Plate VIII

Dokuzeylül B. et al.: Early detection... pp. 261-264

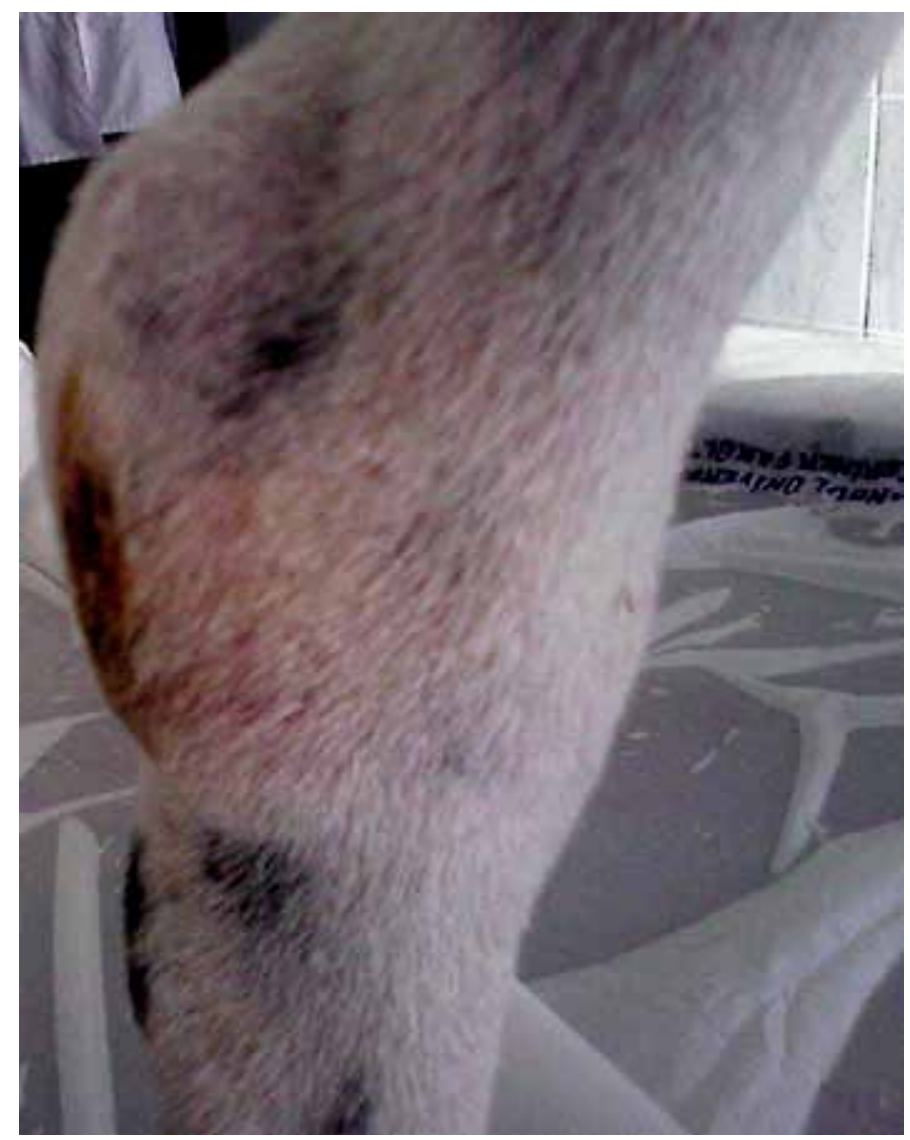

Fig. 1. Swollen joint of the dog in the tibiotarsal area 
Plate IX

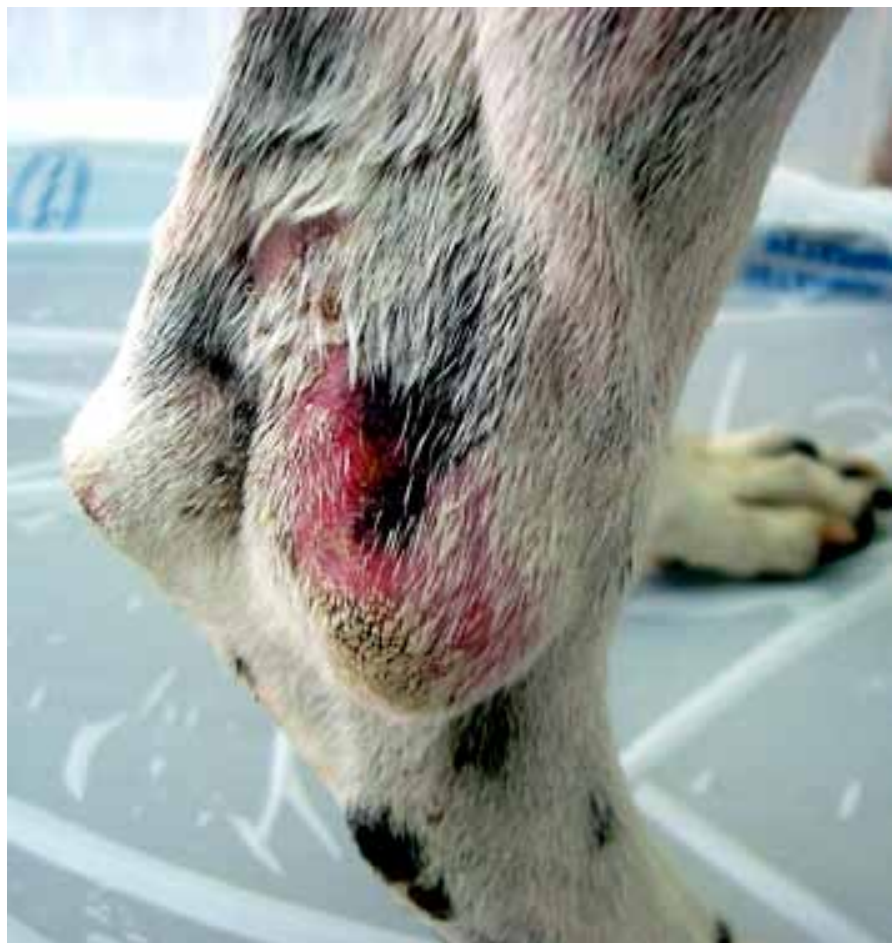

Fig. 2. The appearance of the joint after one week from therapy

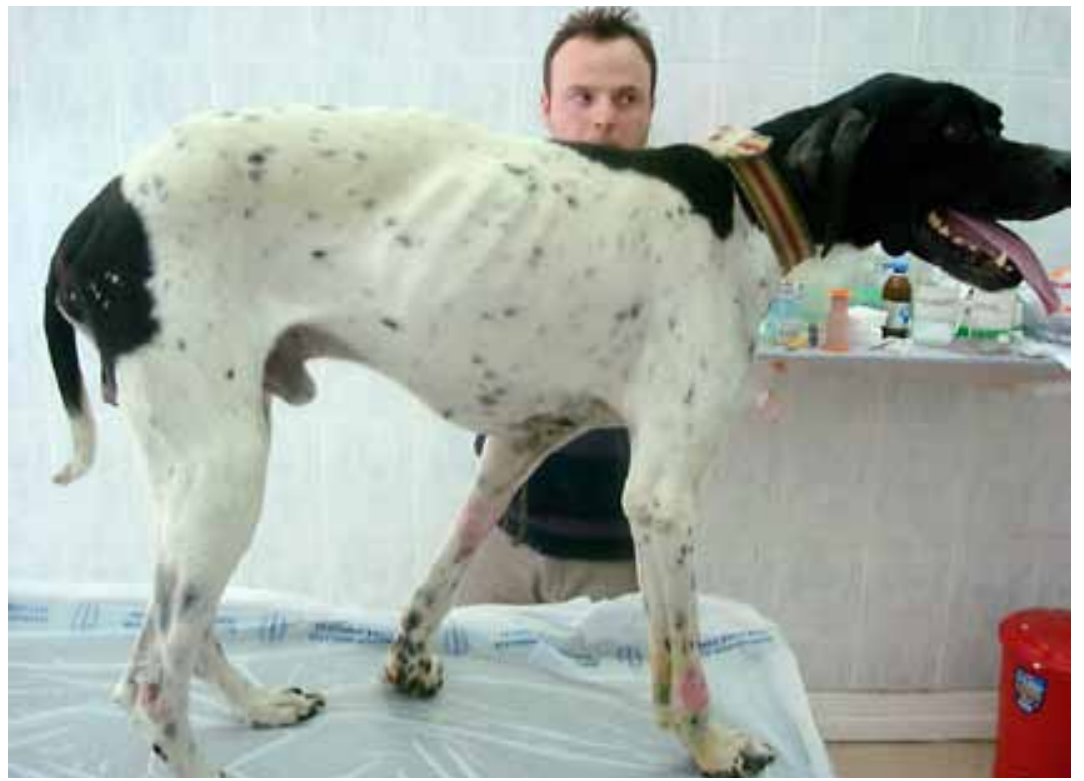

Fig. 3. The dog's physical condition improved after 3 weeks from therapy 